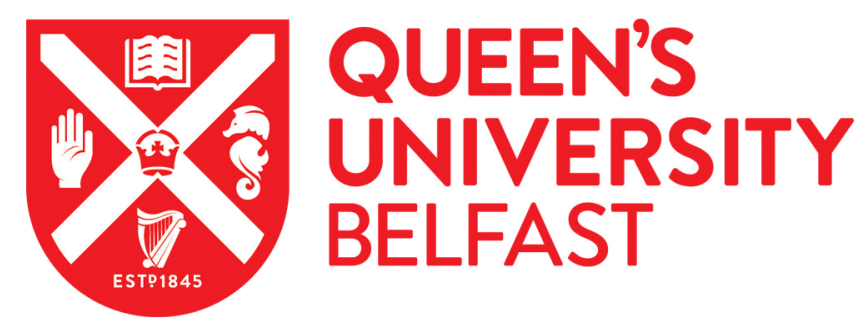

\title{
Residential environment and blood pressure in the prime study: is the association mediated by body mass index and waist circumference?
}

Evans, A., Chaix, B., Ducimetiere, P., Lang, T., Haas, B., Montaye, M., Ruidavets, J. B., Arveiler, D., Amouyel, P., Ferrieres, J., Bingham, A., \& Chauvin, P. (2008). Residential environment and blood pressure in the prime study: is the association mediated by body mass index and waist circumference? Journal of Hypertension, 26(6), 1078-1084.

Published in:

Journal of Hypertension

Queen's University Belfast - Research Portal:

Link to publication record in Queen's University Belfast Research Portal

\section{General rights}

Copyright for the publications made accessible via the Queen's University Belfast Research Portal is retained by the author(s) and / or other copyright owners and it is a condition of accessing these publications that users recognise and abide by the legal requirements associated with these rights.

Take down policy

The Research Portal is Queen's institutional repository that provides access to Queen's research output. Every effort has been made to ensure that content in the Research Portal does not infringe any person's rights, or applicable UK laws. If you discover content in the Research Portal that you believe breaches copyright or violates any law, please contact openaccess@qub.ac.uk. 


\title{
Residential environment and blood pressure in the PRIME Study: is the association mediated by body mass index and waist circumference?
}

\author{
Basile Chaix $^{\mathrm{a}, \mathrm{b}}$, Pierre Ducimetière ${ }^{\mathrm{c}}$, Thierry Lang ${ }^{\mathrm{d}}$, Bernadette Haas ${ }^{\mathrm{e}}$, \\ Michèle Montaye ${ }^{f, g, h}$, Jean-Bernard Ruidavets ${ }^{d}$, Dominique Arveiler ${ }^{\mathrm{e}}$, \\ Philippe Amouyel ${ }^{f, g, h}$, Jean Ferrières ${ }^{d}$, Annie Bingham ${ }^{c}$ and \\ Pierre Chauvin ${ }^{\mathrm{a}, \mathrm{i}}$
}

\begin{abstract}
Objectives Few studies have examined whether social characteristics of the residential environment are associated with blood pressure after controlling for individual sociodemographic characteristics. Even less is known about the processes by which these associations operate. Therefore, we examined whether distinct dimensions of the residential environment (socioeconomic position and urbanicity) were associated with systolic blood pressure. To better understand the processes involved in the associations between contextual factors and blood pressure, we assessed the extent to which these associations were mediated by body mass index and waist circumference.
\end{abstract}

Methods We analysed data from the PRIME Study (7850, 50-60-year-old men surveyed in 1991-1993 in three French regions and recently geocoded on a local scale). We used multilevel regression models to estimate associations between contextual factors and blood pressure, and path analysis to investigate possible mediators of these associations.

Results After adjustment for individual socioeconomic variables, systolic blood pressure increased independently with decreasing municipality population density and decreasing neighbourhood educational level. Path analysis indicated that approximately $37 \%$ of the association between neighbourhood education and blood pressure was statistically explained by the heavier weight and stronger

\section{Introduction}

As living conditions are shaped by the characteristics of the residential environment, an increasing number of studies have started to investigate the impact the neighbourhood environment [1-4] may have on blood pressure, beyond effects of individuals' characteristics. Assessing neighbourhood determinants of high blood pressure is relevant from both an etiological viewpoint and a public health perspective.

Excluding studies based on a questionnaire assessment of hypertension [5,6] and those that did not control for central adiposity of people from deprived neighbourhoods. Approximately $19 \%$ of the association with population density was mediated by anthropometric factors.

Conclusions These data suggest that the neighbourhood environment may influence blood pressure; only part of the associations between contextual factors and blood pressure may operate through body weight and body shape modification. J Hypertens 26:1078-1084 ( 2008 Wolters Kluwer Health | Lippincott Williams \& Wilkins.

Journal of Hypertension 2008, 26:1078-1084

Keywords: blood pressure, residence characteristics, social environment, socioeconomic factors, urbanization

Abbreviation: SD, standard deviation

anserm U707, Research Team on Social Determinants of Health and Healthcare, bUniversité Pierre et Marie Curie-Paris6, UMR-S 707, Paris, ' Inserm U780, Villejuif, dinserm U558 and Toulouse University School of Medicine, Toulouse, eLouis Pasteur University, Faculty of Medicine, EA 1801-Department of Epidemiology and Public Health, Strasbourg, Inserm U744, Public Health and Molecular Epidemiology of Aging-Related Diseases, Lille, Institut Pasteur de

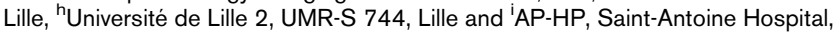
Public Health Unit, Paris, France

Correspondence to Basile Chaix, Inserm UMR-S 707, Faculté de Médecine Saint-Antoine, 27 rue Chaligny, 75012 Paris, France

Tel: +331447386 64; fax: +331447386 63; e-mail: chaix@u707.jussieu.fr

Received 21 May 2007 Revised 18 January 2008

Accepted 18 February 2008 individual socioeconomic variables [7-16], some studies have investigated associations between characteristics of the residential environment and blood pressure. Environmental characteristics considered in those studies pertain to the neighbourhood socioeconomic context [2,17-23], the urbanicity level of the residential area [24], road and air traffic, air and noise pollution [25-28], and the type of local food stores in the vicinity [29].

In the present study, we followed two complementary strategies to extend our understanding of the processes involved in the context-blood pressure associations. 
First, we examined whether distinct dimensions of the residential environment that differently shape living conditions of individuals (i.e., neighbourhood socioeconomic position and urbanicity) were associated with blood pressure, after controlling for individual sociodemographic characteristics. Second, using path analysis [30], we examined whether associations between contextual factors and blood pressure were statistically explained by general obesity and central adiposity. As the present study is the first to investigate mediators between the environment and blood pressure, we only tested a parsimonious mediation model. Even if other risk factors may intervene (physical inactivity, alcohol consumption, smoking, etc.), only body mass index and waist circumference were investigated as potential mediators, as obesity is linked to neighbourhood characteristics [31] and is known as one of the major determinants of blood pressure [32,33].

Some authors have argued that the association between neighbourhood social deprivation and blood pressure may be due to cardiovascular reactivity to stress accumulated over a large number of stressful events $[8,21]$. Showing that associations between neighbourhood social characteristics and blood pressure are mediated to a certain extent by general obesity and body fat distribution would suggest an alternative or complementary hypothesis, providing valuable clues on the environmental causes of high blood pressure.

\section{Methods}

\section{Data sources}

The PRIME Study is a cohort study focused on coronary heart disease. The cohort was recruited between 1991 and 1993 in three centres in France (Lille in the north, Bas-Rhin in the east and Haute-Garonne in the southwest) and one region in Northern Ireland (Belfast) $[34,35]$. In each centre, the sample was composed of about 2600 men aged 50-59 years recruited to match the occupational structure of the background population [35]. The recruitment frame was based on industry, various employment groups, health screening centres and general practices. Subjects were informed of the aim of the study and agreed to participate in a comprehensive health examination and blood testing [35]. Approval from the appropriate local Ethical Committee was obtained in each centre.

Self-administered questionnaires related to demographic, socioeconomic, and lifestyle factors were completed at home by the participants and checked by the technician with the subject at the clinic. Data on education and occupation were directly collected by the technician. During the examination, anthropometric measurements were taken including height and weight without shoes and hip and waist circumferences. As reported in detail previously [35], blood pressure was measured in a quiet room in the sitting position with the right arm on a desk at the heart level after a 5-min rest using an automatic sphygmomanometer (Spengler SP9; Springler, Cachan, France). A standard cuff size was used, but a large cuff was employed if necessary.

The Irish sample was not considered in the present analysis to avoid heterogeneity in the neighbourhood exposures (significant differences exist between France and Ireland in population census years, the census variables, their definition, and the sizes and administrative functions of geographical subdivisions). Thus, the present study used the cross-sectional data of the three French population samples. After excluding 12 individuals with missing value for systolic blood pressure, there were 7838 participants in the database.

\section{Measures}

Systolic blood pressure, body mass index and waist circumference were considered as continuous variables. Questionnaire data allowed us to define the following individual variables: age, antihypertensive medication (yes or no), French citizenship (yes or no), marital status (married/cohabiting or not), number of school years $(0-12, \geq 13)$, employment status (employed, unemployed, other), occupation (high white-collar worker, intermediate occupation, low white-collar worker, bluecollar worker, nonsalaried worker), housing tenure (ownership or renting), and a proxy for material wealth of the household. To determine the latter variable, we adjusted the reported number of cars, number of toilets in the dwelling and number of baths for household size by means of three separate Poisson regression models. We extracted the residuals of each model, standardized them, summed them for each individual to form the indicator, and divided the resulting variable into three categories using the tertiles of the distribution.

Previous analyses of the PRIME Study data [35-37] put the emphasis on regional and national differences in the incidence of coronary heart disease and the prevalence of its risk factors. To investigate spatial variability on a more local scale, we recently used the postal addresses of the French participants in 1991-1993 to precisely geocode them. Eighty-eight percent of the participants were geocoded at the street number or street level, or at the block level or block-group level (groupings of blocks with homogeneous forms of habitat). The others, that is, $12 \%$ participants living in small municipalities not divided into blocks (municipality population $<5000$ ) and the remaining $0.4 \%$ who could not be geocoded at the block-group level, were georeferenced at the municipality level. The median number of inhabitants in the 1387 areas represented in our dataset (block groups or small municipalities), thereafter denominated neighbourhoods, was 1954 (interquartile range: 1033-2583; interdecile range: 433-3465). Participants were also 
considered at the municipality level (663 municipalities in our dataset).

We used the 1990 French population census to define area characteristics. Socioeconomic position and urbanicity were the two clearly distinct contextual dimensions that were considered. Area socioeconomic position was expressed as the proportion of inhabitants with a university degree or equivalent. Following consensus that socioeconomic environment should be considered on a very local scale [1-4], area socioeconomic position was defined at the neighbourhood level. Urbanicity was expressed as population density (number of inhabitants per square kilometre). As differentiation between the urban and the periruban environments takes place on a broader scale than that of the neighbourhood, population density was measured at the municipality level. Contextual variables were divided into four categories containing an equal number of participants.

\section{Statistical analysis}

The small number of participants per neighbourhood (median $=4$; interquartile range: $2-8$ ) did not allow us to reliably assess intra-neighbourhood correlation in systolic blood pressure [38,39]. Nevertheless, we used a multilevel linear regression model with systolic blood pressure as the outcome, including a random effect defined at the neighbourhood level for a more accurate estimation of the parameter variances. The model was systematically adjusted for the recruiting centre and antihypertensive medication use or not, and in a final step for individual sociodemographic covariates. We estimated associations between the two contextual variables each divided into four categories and blood pressure, first by including three dummy variables into the model and then by entering a variable coded from 1 to 4 as a test of linear trend.

Finally, using Mplus 4.2. [40], we estimated a path analysis model [30] to assess whether body mass index and waist circumference mediated any part of the associations between contextual factors and blood pressure. This model, adjusted for individual sociodemographic variables, considered contextual factors as ordinal variables coded from 1 to 4 . We specified both a direct effect of contextual variables on blood pressure and an indirect effect of contextual variables on blood pressure mediated by body mass index and waist circumference. It allowed us to approximately assess the proportion of the associations between contextual factors and blood pressure that was statistically explained by obesity [30]; this proportion was cautiously interpreted as it would be biased in case of major confounding of the obesity-blood pressure association [41].

\section{Results}

As shown in Table 1, the mean systolic blood pressure was $134 \mathrm{mmHg}$ (interquartile range: $120-144$ ). Thirty-
Table 1 Descriptive data for the main variables, PRIME Study, 1991-1993, $n=7838$

\begin{tabular}{ll}
\hline Age [mean (SD)] & $54.9[2.9]$ \\
Systolic blood pressure in mmHg [mean (SD)] & $134[18]$ \\
Diastolic blood pressure in $\mathrm{mmHg}$ [mean (SD)] & $84[12]$ \\
Antihypertensive medication (\%) & 14.3 \\
Body mass index [mean (SD)] & $26.7[3.5]$ \\
Obese individuals (\%) & $15.6 \%$ \\
Waist circumference in cm [mean (SD)] & $95.9[10.0]$ \\
Non-French citizens (\%) & 4.7 \\
Living alone (\%) & 12.3 \\
Number of school years [mean (SD)] & $11.4[3.8]$ \\
High white-collar workers (\%) & 24.9 \\
Blue-collar workers (\%) & 27.6 \\
Unemployed (\% in active population) & 7.9 \\
Municipality population density [mean number of & $2119[1936]$ \\
inhabitants/km ${ }^{2}$ (SD)] & \\
Proportion with a university degree in the neighbourhood & $6.4[5.3]$ \\
[\%, mean (SD)] & \\
\hline
\end{tabular}

$\mathrm{SD}$, standard deviation.

four percent of the participants had a systolic blood pressure equal to or greater than $140 \mathrm{mmHg}$. Overall, $14 \%$ received antihypertensive medication. About $16 \%$ of the participants were obese (body mass index $>30 \mathrm{~kg} / \mathrm{m}^{2}$ ).

As shown in Table 2, we first estimated a multilevel model for each of the two contextual variables. These models were adjusted for study centre and antihypertensive medication use (but not for the other individual variables). We found that systolic blood pressure monotonously increased with decreasing population density of the municipality. We also noted a strong and monotonous increase in blood pressure with decreasing educational level of the neighbourhood.

The correlation between neighbourhood education and municipality population density considered at the individual level was equal to 0.22 (95\% confidence interval: $0.20-0.24$ ), and judged not to be too high to disentangle their predictive role. The two contextual factors were then introduced simultaneously in a model also adjusted

\begin{tabular}{|c|c|c|}
\hline & Coefficient & $95 \% \mathrm{Cl}$ \\
\hline \multicolumn{3}{|l|}{ Model 1} \\
\hline \multicolumn{3}{|c|}{ Municipality population density (vs. high) } \\
\hline Mid-high & +0.7 & $-0.5,+1.9$ \\
\hline Mid-low & +1.5 & $+0.4,+2.6$ \\
\hline Low & +2.5 & $+1.3,+3.6$ \\
\hline Trend test & & $P<0.001$ \\
\hline \multicolumn{3}{|l|}{ Model 2} \\
\hline \multicolumn{3}{|c|}{ Neighbourhood educational level (vs. high) } \\
\hline Mid-high & +1.1 & $+0.1,+2.2$ \\
\hline Mid-low & +1.4 & $+0.4,+2.5$ \\
\hline Low & +3.3 & $+2.2,+4.4$ \\
\hline Trend test & & $P<0.001$ \\
\hline
\end{tabular}

The coefficients represent adjusted differences in mean blood pressure in $\mathrm{mmHg}$, relative to the reference category. $\mathrm{Cl}$, confidence intervals. The two contextual factors were included separately in models 1 and 2. Cutoffs to categorize the contextual variables were 350,1600 , and 3200 inhabitants per $\mathrm{km}^{2}$ for population density and 3,5 , and $9 \%$ for the neighbourhood percentage with a university degree. 
Table 3 Associations between individual and contextual factors and blood pressure, from a multilevel model including individual and contextual variables simultaneously, PRIME Study, 1991-1993, $n=7838$

\begin{tabular}{lcc}
\hline & Coefficient & $95 \% \mathrm{Cl}$ \\
\hline Study centre (vs. Toulouse) & & \\
$\quad$ Lille & +12.0 & $+10.9,+13.2$ \\
Strasbourg & +8.4 & $+7.4,+9.5$ \\
Individual factors & & \\
Age (5-year increase) & +2.7 & $+2.0,+3.4$ \\
Antihypertensive medication & +15.1 & $+14.0,+16.1$ \\
Non-French vs. French citizenship & -1.7 & $-3.4,+0.1$ \\
Alone vs. married/cohabiting & +0.2 & $-1.0,+1.4$ \\
Low number of school years & +1.6 & $+0.6,+2.5$ \\
Occupation (vs. high white-collar worker) & & \\
$\quad$ Nonsalaried worker & +0.3 & $-1.4,+2.1$ \\
$\quad$ Intermediate occupation & +1.2 & $+0.1,+2.3$ \\
$\quad$ Low white-collar worker & +1.4 & $-0.1,+2.8$ \\
$\quad$ Blue-collar worker & +2.4 & $+1.2,+3.7$ \\
Unemployed vs. employed & +0.8 & $-0.6,+2.2$ \\
Material wealth (vs. high level) & & \\
$\quad$ Medium level & +0.8 & $-0.2,+1.7$ \\
$\quad$ Low level & +1.4 & $+0.4,+2.4$ \\
$\quad$ Trend test & & $P=0.007$ \\
Renting dwelling vs. ownership & -0.8 & $-1.8,-0.3$ \\
Contextual factors & & \\
Municipality population density (vs. high) & & \\
$\quad$ Mid-high & +0.5 & $-0.9,+1.3$ \\
$\quad$ Mid-low & +1.3 & $+0.1,+2.5$ \\
$\quad$ Low & & $+0.6,+3.2$ \\
$\quad$ Trend test & & \\
Neighbourhood educational level (vs. high) & & \\
Mid-high & +0.2 & $-0.9,+1.3$ \\
Mid-low & +0.1 & $-1.0,+1.2$ \\
$\quad$ Low $\quad$ Trend test & +1.5 & $+0.3,+2.7$ \\
$\quad$ & $P=0.025$ \\
\hline
\end{tabular}

The coefficients represent adjusted differences in mean blood pressure in $\mathrm{mmHg}$, relative to the reference category. $\mathrm{Cl}$, confidence interval.

for all individual sociodemographic variables. As shown in Table 3, a higher blood pressure was observed among older and low-educated persons. After adjustment for other individual variables, dose-response associations indicated a monotonous increase of blood pressure with decreasing occupational status and decreasing level of material wealth.

The associations between municipality population density and neighbourhood education on one hand and blood pressure on the other were reduced after mutual adjustment and adjustment for individual sociodemographic characteristics. Despite that, residing in a lowpopulation-density municipality and in a low-education neighbourhood remained a significant predictor of a higher systolic blood pressure. Tests for linear trends confirmed that blood pressure increased with decreasing municipality population density and decreasing neighbourhood education.

Our final objective was to assess whether these associations between area factors and blood pressure were mediated by body mass index and waist circumference. The path analysis model estimated is depicted in Fig. 1 (model adjusted for individual variables). In this model, both a high neighbourhood educational level and a high municipality population density were associated with a lower body mass index and a smaller waist circumference. Therefore, the associations between the two contextual factors and body mass index and waist circumference were in the same direction as the associations between the contextual variables and blood pressure. As such, the two anthropometric variables, as strong predictors of blood pressure, constitute potential mediators of associations between contextual factors and blood pressure. As shown in Fig. 1, the indirect effects of both municipality population density and neighbourhood education (through body mass index and waist circumference) were statistically significant. After taking those indirect effects into account, the direct (residual) effect of municipality population density on blood pressure remained statistically significant, but that of neighbourhood education did not. We found that approximately $37 \%$ of the association between neighbourhood education and blood pressure was statistically explained by body mass index and waist circumference as opposed to only approximately $19 \%$ of the association between municipality population density and blood pressure.

\section{Discussion}

The present study suggests that characteristics of the residential environment were associated with blood pressure, besides effects of individual socioeconomic variables. The strength of the present study includes the attempt to disentangle the predictive role of two clearly distinct dimensions of the residential environment and our quantification of the extent to which anthropometric parameters mediated associations between contextual factors and blood pressure. Limitations of the present work include the cross-sectional design of our observational study, the absence of repeated measurements of blood pressure over time, and the fact that we could only assess general characteristics of the environment rather than specific features that may be relevant to blood pressure (sport amenities [42], food environment [43], healthcare resources, etc.). Also, our findings should not be generalized to other populations.

Coherently with a previous study from the WHO MONICA Project [44], large differences in blood pressure were observed between study centres. Disparities were also found for body mass index and waist circumference: $+0.9 \mathrm{~kg} / \mathrm{m}^{2}$ (95\% confidence interval: $0.7-1.1$ ) and $+3.7 \mathrm{~cm}$ of waist circumference $(95 \%$ confidence interval: 3.1-4.2) in Strasbourg than in Toulouse after adjustment for individual sociodemographic characteristics. It is not clear whether between-centre disparities in blood pressure are attributable to true differences between regions, a different recruitment frame in the three centres and/or residual differences in the measurement process (relationship with survey technicians, 
Fig. 1

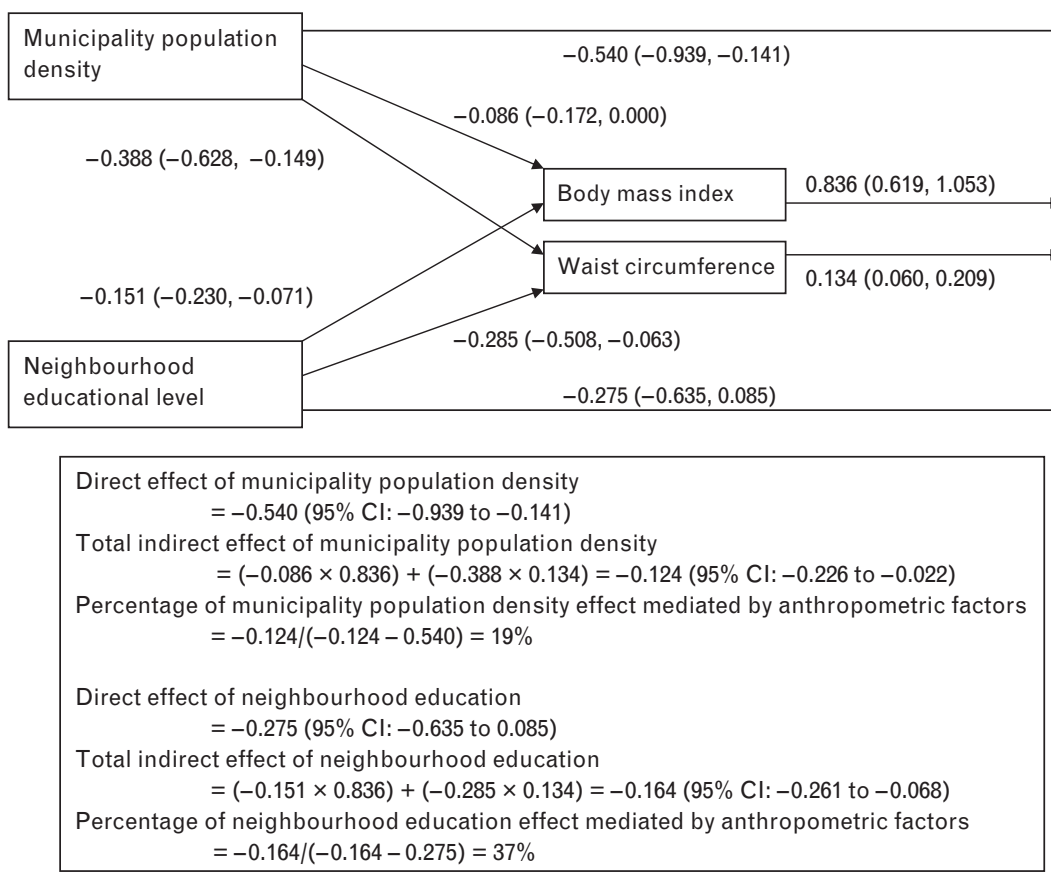

Graphical display of the path analysis model. The three regression equations with body mass index, waist circumference and blood pressure as the outcomes are adjusted for all the individual sociodemographic covariates (not reported in the figure). The equation for blood pressure is also adjusted for body mass index and waist circumference. Note: coefficients of associations with body mass index are in $\mathrm{kg} / \mathrm{m}^{2}$, with waist circumference in $\mathrm{cm}$, and with systolic blood pressure in $\mathrm{mmHg}$. As shown at the bottom of the figure, the product of the coefficients along a compound path reflects the weight of that path. $95 \% \mathrm{Cl}$ indicates $95 \%$ confidence interval.

quietness of the room, etc.). Accordingly, analyses were systematically adjusted for study centre.

Another reason to control for study centre was our aim to extend previous PRIME studies [35-37] that focused on regional differences in risk factors by investigating spatial variability in blood pressure on the more local scale of the neighbourhoods. There are differences between study centres in municipality population density and neighbourhood educational level (Lille has a higher population density, and Toulouse a higher neighbourhood educational level, $P<0.001$, Kruskal-Wallis test); despite that, there is a substantial overlap in the distributions of contextual factors between the three centres. Adjusting for study centre allowed us to remove the large blood pressure differences observed on the broad regional scale and assess whether local differences in neighbourhood characteristics within each centre had an additional impact on blood pressure.

As in previous studies [2,19], an independent association was found between neighbourhood socioeconomic position and systolic blood pressure. Our strategy to better understand this association was to assess the mediating role of general obesity and central adiposity, as they may be in the pathway between residential environment and blood pressure.
A path analysis model indicated that the association between neighbourhood education and blood pressure was partly mediated by anthropometric variables, that is, by the more important body mass index and central adiposity of people from deprived neighbourhoods. This finding is in accordance with the fact that the obesity risk increases with deprivation level of the neighbourhood (beyond effects of individual socioeconomic variables) [45] and with the major effect of obesity on blood pressure [33]. It provides relevant clues for future etiological research, suggesting that environmental factors relevant to obesity (food environment [43], pedestrian environment and sport facilities [42], neighbourhood social interactions [46], etc.) may play a role in the genesis of blood pressure differences between affluent and deprived neighbourhoods. However, our study does not exclude that other factors (behaviour such as smoking or alcohol consumption, stressful life events $[8,21]$, etc.) also contribute to the association between neighbourhood socioeconomic position and blood pressure.

Regarding urban-rural differences, most studies (all of them conducted in nonindustrialized countries [12-15, 24]) have reported a higher blood pressure in urban areas; however, two studies did not note any urban-rural difference $[47,48]$ and three $[10,11,16]$ found a higher blood pressure in low population density territories. Population 
density must be understood as antecedent to a set of more proximate risk factors, and its relation to blood pressure may vary from positive to negative in different settings depending on the specific distribution of risk factors across the population density gradient [49]. The urban-rural difference in blood pressure in nonindustrialized countries is not comparable with the urban-periurban contrast considered in our study. The former has been extensively investigated, but the latter has received almost no attention.

The association between population density and blood pressure persisted after adjustment for the anthropometric variables (obesity explained a weaker share of the association with population density than of the association with neighbourhood education). Among other factors, differences in access to care may contribute to this association.

As no previous study explored the mediators between the environment and blood pressure, we found it necessary to start with a parsimonious mediation model, selecting obesity as a candidate mediator because of its major influence on blood pressure [32,33] and demonstrated association with residential environment factors [31]. An extension of our model may be to take into account, in addition to obesity, health behaviour such as physical activity, alcohol consumption or smoking. However, longitudinal data on health behaviour and clinical risk factors and a more complex sequential path analysis model (e.g., environment $\rightarrow$ physical activity $\rightarrow$ obesity $\rightarrow$ hypertension) would be needed to test these relationships.

In summary, our finding that associations between area factors and blood pressure were only partially mediated by obesity does not allow us to draw conclusions on the processes involved in these associations; however, it gives preliminary clues for future research on the environmental causes of blood pressure. Public health strategies to reduce blood pressure disparities between neighbourhoods may need to include transformations of the food landscape, environment for physical activity, and social milieu, and additional individual-based assistance for people for whom the residential environment constitutes an obstacle to behaviour change.

\section{The PRIME Study Group}

The PRIME Study is organized under an agreement between Inserm and the Merck, Sharpe and DohmeChibret Laboratory, with the following participating laboratories:

- The Strasbourg MONICA Project, Department of Epidemiology and Public Health - EA1801, Université Louis Pasteur, Faculté de Médecine, Strasbourg, France (D. Arveiler, B. Haas).
- The Toulouse MONICA Project, Inserm, U558; Department of Epidemiology, Université Paul Sabatier - Toulouse Purpan, Toulouse, France (J. Ferrières, J.-B. Ruidavets).

- The Lille MONICA Project, Inserm, U744, Lille; Institut Pasteur de Lille, Lille; Université de Lille 2, Lille, France (P. Amouyel, M. Montaye).

- The Department of Epidemiology and Public Health, Queen's University, Belfast, Northern Ireland (A. Evans, J. Yarnell, F. Kee).

- The Department of Atherosclerosis, Inserm, U545, Lille; Institut Pasteur de Lille, Lille; Université de Lille 2, Lille, France (G. Luc, J.-M. Bard).

- The Laboratory of Haematology, Inserm, U626, Marseille, Hôpital La Timone, Marseille, France (I. Juhan-Vague, P. Morange).

- The Laboratory of Endocrinology, Inserm U563, Toulouse, France (B. Perret).

- The Vitamin Research Unit, The University of Bern, Bern, Switzerland (F. Gey).

- The Nutrition and Metabolism Group, Centre for Clinical and Population Sciences, Queen's University Belfast, Northern Ireland (J. Woodside, I. Young).

- The DNA Bank, Inserm U525, Paris, France (F. Cambien).

- The Coordinating Centre, Inserm, U780, Villejuif, France (P. Ducimetière, A. Bingham).

\section{Acknowledgements}

B.C. is supported by the French National Research Agency (Agence Nationale de la Recherche, Programme Santé-Environnement \#00153 05), and by a grant from Région Île-de-France. B.C. and P.C. are supported by a research grant from the City of Paris. The authors thank the following organizations which allowed the recruitment of the PRIME participants: the Health screening centres organized by the Social Security of Lille (Institut Pasteur), Strasbourg, Toulouse, and Tourcoing; Occupational Medicine Services of Haute-Garonne, of the Urban Community of Strasbourg; the Association Interentreprises des Services Médicaux du Travail de Lille et environs; the Comité pour le Développement de la Médecine du Travail; the Mutuelle Générale des PTT du Bas-Rhin; the Laboratoire d'Analyses de l'Institut de Chimie Biologique de la Faculté de Médecine de Strasbourg; the Department of Health (NI) and the Northern Ireland Chest Heart and Stroke Association. We also thank the members of the event validation committees: Professor L. Guize, Dr C. Morrison, Dr M.-T. Guillanneuf, Professor M. Giroud; and the Alliance Partnership Programme for its financial support.

There are no conflicts of interest.

\section{References}

1 Diez-Roux AV, Merkin SS, Arnett D, Chambless L, Massing M, Nieto FJ, et al. Neighborhood of residence and incidence of coronary heart disease. N Engl J Med 2001; 345:99-106. 
2 Diez-Roux AV, Nieto FJ, Muntaner C, Tyroler HA, Comstock GW, Shahar E, et al. Neighborhood environments and coronary heart disease: a multilevel analysis. Am J Epidemiol 1997; 146:48-63.

3 Chaix B, Rosvall M, Merlo J. Recent increase of neighborhood socioeconomic effects on ischemic heart disease mortality: a multilevel survival analysis of two large Swedish cohorts. Am J Epidemiol 2007; 165:22-26.

4 Chaix B, Rosvall M, Merlo J. Neighborhood socioeconomic deprivation and residential instability: effects on incidence of ischemic heart disease and survival after myocardial infarction. Epidemiology 2007; 18:104-111.

5 Cubbin C, Sundquist K, Ahlen H, Johansson SE, Winkleby MA, Sundquist J. Neighborhood deprivation and cardiovascular disease risk factors: protective and harmful effects. Scand J Public Health 2006; 34:228-237.

6 Diez-Roux AV, Link BG, Northridge ME. A multilevel analysis of income inequality and cardiovascular disease risk factors. Soc Sci Med 2000; 50:673-687.

7 Jackson RW, Treiber FA, Turner JR, Davis H, Strong WB. Effects of race, sex, and socioeconomic status upon cardiovascular stress responsivity and recovery in youth. Int J Psychophysiol 1999; 31:111-119.

8 Harburg E, Erfurt JC, Chape C, Hauenstein LS, Schull WJ, Schork MA. Socioecological stressor areas and black-white blood pressure: Detroit. J Chronic Dis 1973; 26:595-611.

9 Garcia-Palmieri MR, Sorlie PD, Havlik RJ, Costas R Jr, Cruz-Vidal M. Urbanrural differences in 12 year coronary heart disease mortality: the Puerto Rico Heart Health Program. J Clin Epidemiol 1988; 41:285-292.

10 Miall WE, Kass EH, Ling J, Stuart KL. Factors influencing arterial pressure in the general population in Jamaica. BMJ 1962; 2:497-506.

11 Pukhlev A, Astrug A, Paskalev T, Sepetliev D. Epidemiological studies of blood pressure in Bulgaria. Cor Vasa 1966; 8:1-9.

12 Mbanya JC, Minkoulou EM, Salah JN, Balkau B. The prevalence of hypertension in rural and urban Cameroon. Int J Epidemiol 1998; 27:181 185.

13 van der Sande MA, Milligan PJ, Nyan OA, Rowley JT, Banya WA, Ceesay $\mathrm{SM}$, et al. Blood pressure patterns and cardiovascular risk factors in rural and urban Gambian communities. J Hum Hypertens 2000; 14:489-496.

14 Singh RB, Sharma JP, Rastogi V, Raghuvanshi RS, Moshiri M, Verma SP, Janus ED. Prevalence of coronary artery disease and coronary risk factors in rural and urban populations of north India. Eur Heart J 1997; 18:17281735.

15 Edwards R, Unwin N, Mugusi F, Whiting D, Rashid S, Kissima J, et al. Hypertension prevalence and care in an urban and rural area of Tanzania. $J$ Hypertens 2000; 18:145-152.

16 M'Buyamba-Kabangu JR, Fagard R, Staessen J, Lijnen P, Amery A. Correlates of blood pressure in rural and urban Zaire. J Hypertens 1987; 5:371-375.

17 Davey Smith G, Hart C, Watt G, Hole D, Hawthorne V. Individual social class, area-based deprivation, cardiovascular disease risk factors, and mortality: the Renfrew and Paisley Study. J Epidemiol Community Health 1998; 52:399-405.

18 McGrath JJ, Matthews KA, Brady SS. Individual versus neighborhood socioeconomic status and race as predictors of adolescent ambulatory blood pressure and heart rate. Soc Sci Med 2006; 63:1442-1453.

19 Cubbin C, Hadden WC, Winkleby MA. Neighborhood context and cardiovascular disease risk factors: the contribution of material deprivation. Ethn Dis 2001; 11:687-700.

20 Gump BB, Matthews KA, Raikkonen K. Modeling relationships among socioeconomic status, hostility, cardiovascular reactivity, and left ventricular mass in African American and White children. Health Psychol 1999; 18:140-150.

21 Wilson DK, Kliewer W, Plybon L, Sica DA. Socioeconomic status and blood pressure reactivity in healthy black adolescents. Hypertension 2000; 35:496-500.

22 Kapuku GL, Treiber FA, Davis HC. Relationships among socioeconomic status, stress induced changes in cortisol, and blood pressure in African American males. Ann Behav Med 2002; 24:320-325.

23 Suchday S, Krantz DS, Gottdiener JS. Relationship of socioeconomic markers to daily life ischemia and blood pressure reactivity in coronary artery disease patients. Ann Behav Med 2005; 30:74-84.

24 Agyemang C. Rural and urban differences in blood pressure and hypertension in Ghana, West Africa. Public Health 2006; 120:525533.

25 van Kempen EE, Kruize H, Boshuizen HC, Ameling CB, Staatsen BA, de Hollander AE. The association between noise exposure and blood pressure and ischemic heart disease: a meta-analysis. Environ Health Perspect 2002; 110:307-317.

26 Madsen C, Nafstad P. Associations between environmental exposure and blood pressure among participants in the Oslo Health Study (HUBRO). Eur J Epidemiol 2006; 21:485-491.
27 Babisch W, Gallacher JE, Elwood PC, Ising H. Traffic noise and cardiovascular risk. The Caerphilly study, first phase. Outdoor noise levels and risk factors. Arch Environ Health 1988; 43:407-414.

28 Babisch W, Ising H, Gallacher JE, Sharp DS, Baker IA. Traffic noise and cardiovascular risk: the Speedwell study, first phase. Outdoor noise levels and risk factors. Arch Environ Health 1993; 48:401-405.

29 Morland K, Diez-Roux AV, Wing S. Supermarkets, other food stores, and obesity: the atherosclerosis risk in communities study. Am J Prev Med 2006; 30:333-339.

30 Ditlevsen S, Christensen U, Lynch J, Damsgaard MT, Keiding N. The mediation proportion: a structural equation approach for estimating the proportion of exposure effect on outcome explained by an intermediate variable. Epidemiology 2005; 16:114-120.

31 Papas MA, Alberg AJ, Ewing R, Helzlsouer KJ, Gary TL, Klassen AC. The built environment and obesity. Epidemiol Rev 2007; 29:129-143.

32 Stamler R, Stamler J, Riedlinger WF, Algera G, Roberts RH. Weight and blood pressure. Findings in hypertension screening of 1 million Americans. JAMA 1978; 240:1607-1610.

33 Garrison RJ, Kannel WB, Stokes J III, Castelli WP. Incidence and precursors of hypertension in young adults: the Framingham Offspring Study. Prev Med 1987; 16:235-251.

34 Ducimetière P, Ruidavets JB, Montaye M, Haas B, Yarnell J. Five-year incidence of angina pectoris and other forms of coronary heart disease in healthy men aged 50-59 in France and Northern Ireland: the Prospective Epidemiological Study of Myocardial Infarction (PRIME) Study. Int $J$ Epidemiol 2001; 30:1057-1062.

35 Yarnell JW. The PRIME Study: classical risk factors do not explain the severalfold differences in risk of coronary heart disease between France and Northern Ireland. Prospective Epidemiological Study of Myocardial Infarction. QJM 1998; 91:667-676.

36 Graille V, Ferrières J, Evans A, Amouyel P, Arveiler D, Luc G, Ducimetière P. Associations between classical cardiovascular risk factors and coronary artery disease in two countries at contrasting risk for myocardial infarction the PRIME Study. Int J Cardiol 2000; 74:191-198.

37 Scarabin PY, Arveiler D, Amouyel P, Dos Santos C, Evans A, Luc G, et al. Plasma fibrinogen explains much of the difference in risk of coronary heart disease between France and Northern Ireland. The PRIME study. Atherosclerosis 2003; 166:103-109.

38 Merlo J. Multilevel analytical approaches in social epidemiology: measures of health variation compared with traditional measures of association. $J$ Epidemiol Community Health 2003; 57:550-552.

39 Chaix B, Merlo J, Subramanian SV, Lynch J, Chauvin P. Comparison of a spatial perspective with the multilevel analytic approach in neighborhood studies: the case of mental and behavioral disorders due to psychoactive substance use in Malmö, Sweden, 2001. Am J Epidemio/ 2005; 162:171 182.

40 Muthén LK, Muthén BO. Mplus user's guide. 3rd ed. Los Angeles, CA: Muthén \& Muthén; 1998-2005.

41 Kaufman JS, Maclehose RF, Kaufman S. A further critique of the analytic strategy of adjusting for covariates to identify biologic mediation. Epidemiol Perspect Innov 2004; 1:4.

42 Humpel N, Owen N, Leslie E. Environmental factors associated with adults participation in physical activity: a review. Am J Prev Med 2002; 22:188199.

43 Glanz K, Sallis JF, Saelens BE, Frank LD. Healthy nutrition environments: concepts and measures. Am J Health Promot 2005; 19:330-333; ii.

44 Merlo J, Asplund K, Lynch JW, Rastam L, Dobson A. Population effects on individual systolic blood pressure - a multilevel analysis of WHO MONICA project. Am J Epidemiol 2004; 159:1168-1179.

45 King T, Kavanagh AM, Jolley D, Turrell G, Crawford D. Weight and place: a multilevel cross-sectional survey of area-level social disadvantage and overweight/obesity in Australia. Int J Obes 2006; 30:281-287.

46 Glass TA, Rasmussen MD, Schwartz BS. Neighborhoods and obesity in older adults: the Baltimore memory study. Am J Prev Med 2006; 31:455463.

47 Beiser M, Collomb H, Ravel JL, Nafziger CJ. Systemic blood pressure studies among the Serer of Senegal. J Chronic Dis 1976; 29:371-380.

48 Nair P, Nyamphisi M, Yarnell JW. Lack of difference in blood pressure between the urban and rural population in Lesotho, Africa. Cent Afr J Med 1994; 40:278-281.

49 Kaufman JS, Owoaje EE, James SA, Rotimi CN, Cooper RS. Determinants of hypertension in West Africa: contribution of anthropometric and dietary factors to urban-rural and socioeconomic gradients. Am J Epidemiol 1996; 143:1203-1218. 